\title{
Patients' pathways to cancer care in Tanzania: documenting and addressing social inequalities in reaching a cancer diagnosis
}

Fortunata Songora Makene ${ }^{1}$, Richard Ngilangwa' ${ }^{1}$ Cristina Santos ${ }^{2}$, Charlotte Cross $^{2}$, Twalib Ngoma ${ }^{3}$, Phares G. M. Mujinja ${ }^{3}$, Marc Wuyts ${ }^{4}$ and Maureen Mackintosh ${ }^{2 *}$ (1)

\begin{abstract}
Background: This article investigates the extent and sources of late diagnosis of cancer in Tanzania, demonstrating how delayed diagnosis was patterned by inequities rooted in patients' socio-economic background and by health system responses. It provides evidence to guide equity-focused policies to accelerate cancer diagnosis.

Methods: Tanzanian cancer patients (62) were interviewed in 2019. Using a structured questionnaire, respondents were encouraged to recount their pathways from first symptoms to diagnosis, treatment, and in some cases checkups as survivors. Patients described their recalled sequence of events and actions, including dates, experiences and expenditures at each event. Socio-demographic data were also collected, alongside patients' perspectives on their experience. Analysis employed descriptive statistics and qualitative thematic analysis.
\end{abstract}

Results: Median delay, between first symptoms that were later identified as indicating cancer and a cancer diagnosis, was almost 1 year (358 days). Delays were strongly patterned by socio-economic disadvantage: those with low education, low income and non-professional occupations experienced longer delays before diagnosis. Health system experiences contributed to these socially inequitable delays. Many patients had moved around the health system extensively, mainly through self-referral as symptoms worsened. This "churning" required out-of-pocket payments that imposed a severely regressive burden on these largely low-income patients. Causes of delay identified in patients' narratives included slow recognition of symptoms by facilities, delays in diagnostic testing, delays while raising funds, and recourse to traditional healing often in response to health system barriers. Patients with higher incomes and holding health insurance that facilitated access to the private sector had moved more rapidly to diagnosis at lower out-ofpocket cost.

Conclusions: Late diagnosis is a root cause, in Tanzania as in many low- and middle-income countries, of cancer treatment starting at advanced stages, undermining treatment efficacy and survival rates. While Tanzania's policy of free public sector cancer treatment has made it accessible to patients on low incomes and without insurance, reaching a diagnosis is shown to have been for these respondents slower and more expensive the greater their socio-economic disadvantage. Policy implications are drawn for moving towards greater social justice in access to cancer care.

Keywords: Cancer, Patients' pathways, Diagnosis, Access, Inequality, Delay, Costs, Disadvantage

*Correspondence: Maureen.Mackintosh@open.ac.uk

2 Faculty of Arts and Social Sciences, The Open University, Walton Hall,

Milton Keynes MK7 6AA, UK

Full list of author information is available at the end of the article

\section{Background}

This article analyses structured narratives by 62 Tanzanian cancer patients interviewed in 2019. The analysis focuses on the patterning by socio-economic inequality 
of the time elapsed, pathway patterns and costs of reaching a cancer diagnosis for these respondents. The article documents the socially unjust, regressive impact of delay on the costs experienced by these respondents in their search for diagnosis. It identifies implications for interventions that could make cancer diagnosis more rapid and accessible, and less socially inequitable, thus contributing towards more equitable Universal Health Coverage (UHC).

Access to cancer care in low-resource settings poses a major challenge for UHC. Tanzania was classified by the World Bank as a low-income country until 2020, now lower-middle income, with an estimated population of 58 million in 2019 [1]. Current health expenditure per head was just USD 37 in $2018^{1}$; of that, $24 \%$ was funded out-of-pocket, $1 \%$ from private insurance, $8 \%$ from social insurance (National Health Insurance Fund (NHIF)), 32\% external funding, and 35\% from domestic government expenditure [2].

The Tanzanian public health system is hierarchically structured. The primary level includes dispensaries and health centres and community outreach. District hospitals refer upwards as required to regional, then zonal and national including specialist hospitals. There are also government-supported and independent religious health facilities (17\% of all registered facilities) and private facilities (18\%) ([3]: 138).

Tanzania is experiencing rising cancer incidence and mortality [4] and is increasing the number of cancer treatment centres. Of 40,464 new cases in 2020, the leading cancers were cervical $(25 \%)$, breast $(10 \%)$ and prostate (9\%) [5]. There is at present no systematic community-based screening for early-stage cancers; there is facility-based opportunistic screening capability for cervical cancer using Visual Inspection with Acetic Acid or Lugol's Iodine [6]. In 2019, cancer treatment was available at one national specialist public hospital (Ocean Road Cancer Institute (ORCI)), in three zonal public referral hospitals, and in two private hospitals including Aga Khan hospital in the commercial capital, Dar es Salaam. Recognising that the high cost of chemotherapy and radiotherapy is a source of financial hardship and catastrophic spending for low-income populations [7], the Tanzanian government has exempted cancer patients from paying for treatment since introducing charging (cost sharing) into the public health sector in 1993. However, cancer patients continue to pay for other inpatient treatment, such as surgery and transfusions, and for diagnostic investigations and other medication.

\footnotetext{
${ }^{1}$ Spending per head at current exchange rate; USD 112 at Purchasing Power Parity [2].
}

In Tanzania as in many low- and middle-income countries (LMICs) most cancer patients are diagnosed late, reaching treatment only at late stages [8-10]. This sharply reduces treatment efficacy and survival rates [11-13] and multiplies the cost burden for patients and the health services. The gap between need and access to treatment remains wide [14] since many cancer sufferers in Tanzania are known to "never reach" treatment centres [15]. Accelerating diagnosis is thus a key Tanzanian policy objective [9], requiring an understanding of the sources of delay including inequity in barriers to care.

\section{Methods \\ Data collection}

This study used a structured qualitative research tool designed to explore barriers and facilitators experienced by cancer patients and survivors in Tanzania, along their pathways to and through cancer care, including interconnections between their experience and socio-economic status.

No sampling frame exists for selecting a representative sample of cancer sufferers and survivors in Tanzania. Respondents undergoing cancer treatment who were willing and able to be interviewed were recruited with medical staff assistance. At ORCI, the public specialist cancer referral hospital, two patient volunteers were requested from every other in-patient ward (40 patients), spreading the sample across the hospital. At Aga Khan Hospital, a faith-based private hospital, volunteers were requested both at the hospital and by contacting every fourth person on a data base of those under treatment; seven people agreed to an interview. To learn more of patients' experiences at regional hospital level, nine interviewees with recent cancer diagnoses were recruited at Kitete (Tabora) or Tumbi (Pwani) regional hospitals (small numbers since these hospitals cannot currently offer treatment). Six cancer survivors were also recruited in Dar es Salaam with the assistance of survivors' groups. The resultant convenience sample offered a wide spread of patients' background and experience as the Results section confirms.

There was no selection of patients by type of cancer. The interview tool, attached as Supplementary material, drew on medical and health systems literature on clinical and care pathways $[16,17]$, but aimed particularly to contribute to the expanding exploratory qualitative literature on patients' pathways to care in African contexts [18-21] especially patients' experience including costs and other barriers to access [22, 23].

The interviews took the form of a structured conversation between interviewer and respondent, guided by the questionnaire. Respondents defined freely each event as they recalled it, from experiencing the symptoms later 
identified as indicating cancer (henceforth "first symptoms") to diagnosis, treatment and beyond. For each event, the interviewees were asked: when or how long ago each occurred; what happened (e.g. symptoms worsened, returned for test results); where it occurred and what was done; and costs incurred including out-of-pocket (OOP) payments, costs covered by insurance or other sources, and travel costs.

Additional socio-demographic information included age, sex, schooling, current estimated monthly household income, place of residence and occupational status (current and before the onset of illness). Final questions covered use of alternative health treatments; insurance arrangements; participants' social support and information networks; and open comments on their experience.

There was no audio recording. Interviewers recorded responses in writing, after a discussion if required to agree a response to each question; occasionally a lengthy or complex response was summarised. The interview tool was prepared in English and translated into and administered in Kiswahili. Responses were noted in Kiswahili, subsequently translated into English by each interviewer, and finally checked by supervisors. ${ }^{2}$ Participants shared these painful stories either privately or in a room with other patients or with carers who provided support. Participants did express a wish to tell their stories, and several said that they had felt listened to.

This research formed part of a larger collaborative project, Innovation for Cancer Care in Africa. ${ }^{3}$ Signed consent forms specified objectives and study content, privacy, data security, voluntary participation, and how to follow up.

\section{Data analysis}

This article presents a structured qualitative analysis of elements of a substantial data set: 62 interviewees describing 906 events, plus additional data. The article uses both descriptive statistical analysis and thematic narrative analysis to analyse characteristics of patients' pathways up to and including diagnosis, and to provide evidence of reasons for the delays observed.

The data set was coded numerically to identify socioeconomic groups, to locate key milestones on each pathway (e.g, date of first experiencing symptoms, first health

\footnotetext{
${ }^{2}$ There was no further back-translation from English to Kiswahili to crosscheck.

${ }^{3}$ See funding statement and acknowledgements. The broader project brings together researchers from Tanzania, Kenya, India and the UK to investigate the opportunities and challenges of linking industrial development and health systems innovation in order to widen access to cancer care in Tanzania and Kenya. In Tanzania 21 health professionals were also interviewed individually, alongside focus group discussions in each hospital. These interviews are not analysed here.
}

facility visit, event when cancer diagnosed), and to identify levels and sector of all facilities visited. Descriptive statistical analysis used Stata 14.

Descriptive statistical findings provide evidence of the variation in extent of delay before diagnosis, and the patterning of delays by socio-economic background and by other relevant quantifiable variables such as outof-pocket spending and insurance arrangements. The empirical distributions of the variables in the descriptive statistical analysis are asymmetric and strongly skewed with the tail stretching towards larger values. The findings are therefore presented using order-based rather than mean-based summary measures. The tables list sample size $(\mathrm{N})$ and three-number summaries: the lower quartile, median and upper quartile of each empirical distribution. This presentation allows inspection of degree of skewness, a relevant dimension of the data for exploring socio-economic inequality.

Thematic qualitative analysis was also conducted of patients' narrative responses, to identify reasons given for delay and to explore how these were related to individuals' socio-economic characteristics. Thematic coding used NVivo12, with the data uploaded in survey mode. A priori coding used the preidentified themes in the questionnaire, including symptoms, diagnostic tests, costs, travel. Additional coding identified themes relevant to explaining delay, including referral (and lack of referral), funding sources, reasons for moving between providers.

The presentation of results combines descriptive statistics to identify patterns in the data and narrative cases, summarising experiences of selected individual patients, chosen to illustrate identified themes contributing to explanation of delays and their patterning by dimensions of socio-economic inequality. This use of descriptive statistical analysis in association with explanatory narrative case material is an accepted approach to qualitative research and analysis in social science [24]. Descriptive statistics identify patterns and allow cross checking of typicality of emergent themes, thereby helping to establish that findings from thematic analysis are indeed characteristic of the whole set of individuals studied ("internal generalizability") while making no inferences beyond the sample ([24]: 477-8).

\section{Results}

Descriptive statistical analysis demonstrates that the most disadvantaged patients in our data set generally faced the longest delays before diagnosis. A combination of descriptive statistics and narrative case studies of patients' experience identify key reasons for delay and their patterning by disadvantage. The results starkly foreground the socially unjust cumulative impact of these factors in delaying cancer diagnosis while imposing a 
Table 1 Level of education and occupation before illness (number of respondents)

\begin{tabular}{lllll}
\hline $\begin{array}{l}\text { Occupational } \\
\text { category }\end{array}$ & \multicolumn{2}{l}{ Education level } & \\
\cline { 2 - 4 } & $\begin{array}{l}\text { Below } \\
\text { primary }\end{array}$ & $\begin{array}{l}\text { Primary } \\
\text { and } \\
\text { secondary }\end{array}$ & $\begin{array}{l}\text { Above } \\
\text { secondary }\end{array}$ & $\begin{array}{l}\text { All } \\
\text { respondents }\end{array}$ \\
\hline $\begin{array}{l}\text { Farmer } \\
\begin{array}{l}\text { Business/ self } \\
\text { employed/ casual } \\
\text { work }\end{array}\end{array}$ & 5 & 15 & 0 & 27 \\
$\begin{array}{l}\text { Professional/ } \\
\text { retired } \\
\text { All respondents }\end{array}$ & 0 & 15 & 0 & 20 \\
\hline
\end{tabular}

Pearson chi2 $(4)=40.986 \operatorname{Pr}=0.000$

Source of all tables and figures: authors' data

severe financial burden on the most disadvantaged of our respondents.

\section{Intersections of disadvantage and delay Indicators of relative disadvantage}

Three indicators of relative deprivation and socio-economic inequality used in this analysis, education level, type of occupation and declared monthly household income, are closely related among our respondents. All those with post-secondary education declared professional occupations (two retired), while those with belowprimary education were predominantly farmers (Table 1 ).

The non-farming business/ self-employed category is broad, from viable businesses through casual labourers; these data do not allow finer distinctions. Declared household income reflects both educational and occupational hierarchies. Farmers' incomes and incomes of those with below-primary education were low and compressed (median TZS 100,000 and 150,000/month respectively (USD 43 and 65)). Most declaring higher incomes held post-secondary qualifications. These socioeconomic indicators did not differ significantly between men and women in the data set.

The cancer patients interviewed in the public sector (in ORCI and two regional hospitals) were overwhelmingly from low income, low education and economically precarious backgrounds. As such, their levels of disadvantage reflect the Tanzanian population. Of 49 such patients (71\% female), $90 \%$ had just primary education or below, including 11 with no formal education. Declared monthly household income of $51 \%$ of interviewees was below TZS 200,000 (USD 87), ${ }^{4}$ and most declared

\footnotetext{
${ }^{4}$ At exchange rate TZS $2300=1$ USD, chosen to reflect exchange rates in late 2019.
}

Table 2 Cumulative time from first symptoms to diagnosis by education level (quartiles of distribution of cumulative days)

\begin{tabular}{lllll}
\hline Education & N & p25 & Median (p50) & p75 \\
\hline Below primary & 15 & 274 & 670 & 1827 \\
Primary/ secondary & 33 & 154 & 381 & 762 \\
Diploma/degree & 10 & 25 & 128 & 276 \\
All respondents & ${ }^{\mathrm{a}} \mathbf{5 8}$ & $\mathbf{1 2 4}$ & $\mathbf{3 5 8}$ & $\mathbf{7 6 3}$ \\
\hline
\end{tabular}

${ }^{a}$ Date of diagnosis is unclear for four respondents

their occupation prior to illness as farmer (55\%), selfemployed business or casual work (18\%), or not working; only three had had professional employment. For comparison, on the Tanzanian Mainland, average household consumption expenditure in 2017/18 was USD 181 ([25]: 8). Employment in agriculture was an estimated $63 \%$ of the total in 2018 [26], while the share of non-agricultural self-employment and casual work in 2014 was estimated at $20 \%$ [27]. Finally, patients interviewed at ORCI came from many regions. These data are consistent with a perception that ORCI treats cancer patients from across Tanzania's social, economic and geographical spectra, not just from a privileged group.

Conversely, the private hospital patients and the Dar es Salaam-based cancer survivors (62\% female) formed a generally less disadvantaged group. Of these 13 respondents, nine had secondary education or above; seven had degrees; and eight declared household incomes of TZS $500,000 /$ month (USD 217) or above.

\section{The association of disadvantage with delay}

Respondents' narratives documented a frequently lengthy search for care: median delay between first symptoms and cancer diagnosis was 358 days. Nearly half had waited over a year, and $28 \%$ more than 2 years for a diagnosis. The extent of this delay was strongly patterned by relative disadvantage.

Length of delay between first symptoms and diagnosis fell steeply and consistently across the distribution as education levels rose (Table 2). The median delay for the least educated category was nearly 2 years (Table 2 ).

Those with professional occupations experienced the shortest delays across the distribution, while selfemployed and casual workers had consistently experienced the longest delays (Table 3).

\section{Sources of delay and facilitators of diagnosis}

What were the main reasons for delay, and why were they so strongly patterned by relative disadvantage in this data set? Patients' narratives identify three key sources of delay: lack of diagnostic capacity and speed, including at regional hospital level; dominance of self-referral within the system as patients struggled to reach a diagnosis; and 
Table 3 Cumulative time from first symptoms to diagnosis by occupational category (quartiles of distribution of cumulative days)

\begin{tabular}{lllll}
\hline Occupational category & N & p25 & Median (p50) & p75 \\
\hline Farmer & 26 & 124 & 387 & 762 \\
Business/ self-employed/ casual & 17 & 425 & 670 & 1493 \\
Professional & 15 & 25 & 135 & 276 \\
All respondents & ${ }^{\mathbf{a}} \mathbf{5 8}$ & $\mathbf{1 2 4}$ & $\mathbf{3 5 8}$ & $\mathbf{7 6 3}$ \\
\hline
\end{tabular}

${ }^{a}$ Date of diagnosis is unclear for four respondents

Table 4 Cumulative time from first visiting a health facility to diagnosis, by level of entry into the formal health system (quartiles of distribution of cumulative days)

\begin{tabular}{lllll}
\hline Level of entry & N & p25 & Median (p50) & p75 \\
\hline Primary & 15 & 152 & 394 & 703 \\
District hospital & 19 & 88 & 290 & 725 \\
Higher level public hospital & 13 & 117 & 547 & 1506 \\
Private sector facility & 11 & 11 & 135 & 336 \\
All respondents & a58 & 58 & 197 & 703 \\
\hline
\end{tabular}

${ }^{a}$ Date of diagnosis is unclear for four respondents

sharply regressive out-of-pocket costs imposing a search for funds and delaying diagnosis. Conversely insurance and private sector access had accelerated diagnosis for the more privileged.

\section{Diagnostic delay and the failure of "by-passing"}

Most of the delay before diagnosis occurred after patients first went to a health facility. At first symptoms, $66 \%$ of respondents said they went directly to a health facility. For the others, the median initial delay was 3 months. Much the longest delays after first going to a facility were again experienced by the least educated group.

Since public sector cancer diagnostic capability is currently concentrated at regional hospital level and above, it was expected that patients who went directly with first symptoms to a higher level facility (often called "bypassing" [28]) would achieve a more rapid diagnosis. Strikingly, this was not case. Patients who had started at the higher level in the public sector had taken longer, across most of the distribution, to reach a diagnosis than those who had started lower down in the public sector; half had waited 1.5 years or more (Table 4 ).

A large majority $(82 \%)$ of respondents went first to a public facility (Table 4), and there was no significant patterning of health system level of entry in the public sector by occupation or education: that is, those "by passing" were not more advantaged. Only starting in the private sector had sharply reduced the delay before diagnosis
(Table 4). Just 11 patients had done so (Table 4), predominantly professionals with higher education.

Patients' narratives show that a lack of diagnostic capacity, particularly at regional hospital level, and especially in pathology for processing biopsies and in imaging, exacerbated by staff shortages and slowness in recognising symptoms, were the main reasons why diagnosis was often slow even at higher levels and why "by-passing" had not been a route to rapid diagnosis for these patients. Case 1 exemplifies several causes of diagnostic delay.

Case $1^{5}$ diagnostic delay at regional level This patient went directly to a regional hospital with first symptoms that could indicate cervical cancer (vaginal discharge, swelling, pain). Over six visits in 6 months, she was given urine tests, medication including antibiotics, and once an ultrasound. As symptoms worsened and wounds opened, she went first to a nearby health centre, then to a dispensary, and was given further medication. She returned to the regional hospital twice, 16 months and 21 months after the first visit, with similar outcomes. She then turned in despair to traditional healing for 6 months, and then for several months to prayer. She returned to the same regional hospital in severe pain three and a half years after the first symptoms. There, she was referred to a private clinic for a biopsy. The patient was then asked by the regional hospital to take the biopsy sample to the national hospital in Dar es Salaam for analysis. Five months later, the diagnostic results were received at the regional hospital. The patient was then referred to ORCI with cervical cancer. (Female patient, self-employed, primary education).

Conversely, where regional diagnostic capability did exist, patients had benefited through rapid diagnosis. For example, one patient (male, below-primary education, farmer) with severe leg symptoms had delayed 3 months before going to hospital. Once there however, the regional hospital took a biopsy, and diagnosed skin cancer within a month. The patient reported that the biopsy cost TZS 200,000 (USD 87).

\section{Self-referred "churning" within the system: a source and response to delay}

A second major source of stress and delay identified from patients' narratives, also well-illustrated in Case 1, was the experience of moving repeatedly between facilities in search of a diagnosis. Just 5 respondents were diagnosed at their first facility (Table 5 Row 2). The more moves in

${ }^{5}$ Cases give authors' summaries of individual patients' trajectories. 
Table 5 Cumulative time to diagnosis by number of moves between health facilities (quartiles of distribution of cumulative days)

\begin{tabular}{lllll}
\hline $\begin{array}{l}\text { Number of moves } \\
\text { between facilities }\end{array}$ & N & p25 & Median (p50) & p75 \\
\hline No move & 5 & 25 & 124 & 454 \\
1 move & 11 & 11 & 117 & 276 \\
2 moves & 20 & 132 & 229 & 777 \\
3 moves & 10 & 274 & 686 & 763 \\
4-8 moves & 12 & 588 & 1010 & 3471 \\
All respondents & 558 & 124 & 358 & 763 \\
\hline
\end{tabular}

${ }^{a}$ Date of diagnosis is unclear for four respondents

search of help, the longer the delays across the distribution before diagnosis (Table 5). ${ }^{6}$

Like the Case 1 patient, $40 \%$ of respondents had moved "downward" in the facility hierarchy while seeking a diagnosis, including over half of those initially "by-passing" to regional or zonal hospitals. Those starting at higher levels had moved around just as much as those who started lower down.

These moves, which we call "churning" within the system, were undertaken largely without formal referral. Among patients not diagnosed at the facility they first visited, 55\% had never been formally referred before diagnosis, yet had moved a median of twice, while the others had at least one referral during their search for diagnosis yet had moved a median of three times. Most moves were thus self-referred: for example, of $16^{7}$ people who started at dispensary or health centre level, just two had been referred upwards; all others reported self-referring to a hospital.

Churning had most seriously affected those with the lowest education: $53 \%$ of those with below-primary education had moved more than twice, as had $41 \%$ of those with primary or secondary education. Conversely, only 1 person with higher education (10\%) and 2 professionals (13\%) had moved more than twice.

Patients' experience was therefore predominantly of self-referred moves in search of help in the face of worsening symptoms rather than patients following pathways structured by the health system, as further illustrated in Case 2.

Case 2 self-referred "churning" and associated delay This patient went directly to a regional hospital

\footnotetext{
${ }^{6}$ Correlation coefficient between number of moves and length of delay $=0.49$.

7 Date of diagnosis of one of these patients is unclear, hence omitted from Table 4.
}

with low back pain. Over several years she went back three times and was given pain medication and her back $\mathrm{X}$-rayed. As stomach pain also developed, she then went successively to a faith-based hospital, a district hospital and a dispensary. Then, struggling with self-described "unstoppable" stomach and back pain, she went back to the district hospital. Imaging and pain management still did not produce a diagnosis. By chance she then went to a free screening session at a church and was told this was cervical cancer. She returned to the same regional hospital, where a biopsy was taken and she was told by the doctor to come back after 3 months for the result. On her return the diagnosis was confirmed. She estimated that by then, she and her family had spent TZS 540,000 (USD 235) on her search. (Female patient, completed primary school, not working (for gain)).

Conversely, some patients' narratives confirm that ability to recognise symptoms at lower levels and formal referral at an early stage could speed up diagnosis, particularly where the referring facility expressed suspicion of cancer. For example, one patient went to a district hospital with stomach pains. The hospital examined her cervix and sent her straight to ORCI. Within a month she was diagnosed and started radiation treatment. (Female, farmer, did not complete primary education). Similarly, a regional hospital with better capability had responded rapidly to a patient referred from a health centre with bleeding, discharge and pain. Although tests took a month to return, the hospital diagnosed uterine cancer within 3 months of the patient first presenting symptoms at a dispensary. (Female patient, farmer, completed primary school).

\section{Use of informal providers and health system delays}

In addition to moves between health facilities, respondents had also visited drug shops, pharmacies and alternative forms of healing, adding to churning and resultant delays. Those with lower education were more likely to move between health facility and informal providers, while $90 \%$ of those with higher education went only to health facilities.

Only four people went to a herbalist or traditional healer before going to a health facility. Seventeen others visited them as part of their search for diagnosis. Case 1 illustrated recourse to traditional healing after many failed attempts to find relief from symptoms within the formal system. Others had followed advice from family and friends. These visits were sometimes influenced by experiences of formal health care; they could thus be both result and cause of delay. Case 3 gives a further example. 
Table 6 Cumulative OOP payments to providers (formal and informal) from first symptoms to diagnosis, by the number of times a patient moved between providers (quartiles of distribution of cumulative payments; Tanzanian shillings; USD in brackets for median payments)

\begin{tabular}{lllll}
\hline $\begin{array}{l}\text { Number of moves } \\
\text { between providers }\end{array}$ & $\mathbf{N}$ & p25 & $\begin{array}{l}\text { Median } \\
\text { (p50) (USD) }\end{array}$ & p75 \\
\hline No move or 1 move & 9 & 0 & $0(0)$ & 200,000 \\
2 moves & 10 & 0 & $34,500(15)$ & 145,000 \\
3 or 4 moves & 12 & 155,000 & $557,000(242)$ & 786,250 \\
5-10 moves & 6 & 298,000 & $436,500(190)$ & $1,508,000$ \\
All respondents & a37 & 2500 & $170,000(74)$ & 700,000 \\
\hline
\end{tabular}

${ }^{a}$ number of patients able to recall $70 \%$ or more of payments per recorded event

Case 3 combining health facility and traditional healer visits A patient with vaginal symptoms was advised by her children to go to a dispensary. There she was given antibiotics and pain killers. Six months later the symptoms had worsened, and, advised by neighbours, she went to traditional healers. Five months later with worsening symptoms she recounted that she decided to stop using local herbs while her daughters were searching for money so that they could take her to hospital. She then went to a faith-based hospital where cervical cancer was diagnosed. (Female patient, primary education, farmer).

\section{Regressive payment burdens as a source of delay}

Patients had faced highly regressive out-of-pocket (OOP) costs, falling most heavily on those with lowest incomes, during their search for diagnosis. The impact on delay was cumulative and fell most heavily on the most disadvantaged.

The cumulative total of OOP payments rose shockingly as "churning" increased (Table 6). ${ }^{8}$ Those who made more than two moves faced strikingly higher payments (Table 6).

The burden of these OOP payments to health providers, including payments to traditional healers, pharmacies and drug shops, was sharply and consistently regressive, imposing the heaviest burden on the most disadvantaged (Table 7). The lowest educated had borne the heaviest absolute payment burden; for those with postsecondary education, the median payment was zero. Our sample necessarily includes only those sufferers who had managed to raise the required money: it is likely others will have dropped out of the search for care.

\footnotetext{
${ }^{8}$ Many respondents were able to recall their payments in considerable detail; to reduce underestimates, results in Tables 6 onwards include only data from respondents able to recall $70 \%$ or more of the payments for events for which payment was required.
}

Table 7 Cumulative OOP payments to providers (formal and informal) from first symptoms to diagnosis, by level of education (quartiles of distribution of cumulative payments; Tanzanian shillings; USD in brackets for median payments)

\begin{tabular}{lllll}
\hline Level of education & N & p25 & $\begin{array}{l}\text { Median } \\
\text { (p50) }\end{array}$ & p75 \\
\hline Below primary & 10 & 170,000 & $547,500(238)$ & 790,000 \\
Primary/ secondary & 19 & 10,000 & $220,000(96)$ & 540,000 \\
Diploma / degree & 8 & 0 & $0(0)$ & 73,750 \\
All respondents & ${ }^{3} 37$ & 2500 & $170,000(74)$ & 700,000 \\
\hline a number of patients able to recall 70\% or more of payments per recorded event
\end{tabular}

Table 8 Household burden of cumulative OOP payments to providers (formal and informal) from first symptoms to diagnosis (quartiles of cumulative payments divided by annual household income)

\begin{tabular}{lllll}
\hline $\begin{array}{l}\text { Bands of declared } \\
\text { household monthly } \\
\text { income }\end{array}$ & N & p25 & $\begin{array}{l}\text { Median } \\
\text { (p50) }\end{array}$ & p75 \\
\hline Up to 150,000 & 12 & 0.068 & 0.366 & 1.325 \\
$160,000-390,000$ & 13 & 0.002 & 0.065 & 0.093 \\
400,000 upwards & 12 & 0 & 0.004 & 0.157 \\
All respondents & a37 & 0.001 & 0.072 & 0.313 \\
\hline
\end{tabular}

a number of patients able to recall $70 \%$ or more of payments per recorded event

Since declared household income rose with education, these regressive payments created a very severe financial burden for the most disadvantaged respondents (Table 8). For over a quarter of the patients in the lowest income band, recorded cumulative OOP payments up to diagnosis exceeded annual declared household income.

Transport costs formed an additional burden exacerbated by churning and distance to higher level hospitals. Median cumulative transport spending up to diagnosis was TZS 83,000 (USD 36), ${ }^{9}$ rising from TZS 16,000 (USD 7) for those diagnosed at their first facility to TZS 92,000 (USD 40) for the majority who moved more than once.

Respondents' narratives indicated that costs of diagnostic tests, some of which required surgery, were a leading source of stress and delay. Table 9 summarises reported payments for imaging (CT scans, ultrasound, MRI), biopsies and surgery, all expensive in relation to reported household incomes (Table 8).

Cases 4 and 5 below illustrate the reported burden of finding money to pay for biopsies and other costs, and the resultant delays.

\footnotetext{
${ }^{9}$ We have transport cost data only for those interviewed in the public sector.
} 
Table 9 OOP payments by type of service purchased at each event from all providers (formal and informal) from first symptoms to diagnosis (quartiles of payments per service; Tanzanian shillings; USD in brackets for median payments)

\begin{tabular}{lllll}
\hline Service paid for & ${ }^{\text {a N }}$ & p25 & $\begin{array}{l}\text { Median } \\
\text { (p50) }\end{array}$ & p75 \\
\hline Admission plus other services & 25 & 30,000 & $115,000(50)$ & 600,000 \\
Imaging, biopsy & 54 & 33,000 & $80,000(35)$ & 200,000 \\
Tests, medication & 80 & 5000 & $14,000(6)$ & 30,000 \\
Consultation, referral & 19 & 5000 & $15,000(7)$ & 50,000 \\
Alternative healing & 28 & 20,000 & $30,000(13)$ & 80,000
\end{tabular}

${ }^{a} \mathrm{~N}$ in this table $=$ number of events at which payments for the service were recorded

Case 4: the financial burden of biopsies and other costs This patient went twice to a dispensary with swelling on the head and was given injections and pain killers. Eight months later with severe headache and more swelling he went twice to a district hospital where he was checked for typhoid and TB and given medication. Four months later with severely worsening symptoms, he underwent a biopsy and blood tests at a faithbased hospital and was told to come back after 2 months. Given a cancer diagnosis, he was referred to a zonal hospital where he received stronger pain medication and a further biopsy confirmed cancer. The two biopsies cost TZS 150,000 and TZS 400,000 respectively (total USD 240 ), and the patient calculated that up to that point the family had spent TZS 640,000 on medical care and TZS 175,000 on transport to facilities (total, USD 344), funded by selling two cows. This patient's declared monthly household income was just TZS 50,000. (Male patient, primary education, farmer).

Case 5: delays arising from costs of tests This patient went to a district hospital with a breast lump and was referred to a zonal hospital. Over four months and in increasing pain, two consecutive biopsies showed no cancer. She then went to three different traditional healers over more than a year. With multiplying symptoms, she then went to a faith-based hospital who referred her back to the zonal hospital. There she was given ultrasound and $\mathrm{X}$-ray examinations, but she lacked the money to pay for a further biopsy. Five months later, advised, she said, by a neighbour whose husband is a doctor, she returned to the zonal hospital where she paid for a biopsy and new ultrasound and X-ray examinations. Two months later she received a cancer diagnosis. The patient could not remember every payment during this lengthy "churning" but calculated that investigations at the zonal hospital totalled TZS 305,000, while the traditional healing
Table 10 Cumulative OOP payments to providers (formal and informal) from first symptoms to diagnosis, by insurance status (quartiles of distribution of cumulative payments; Tanzanian shillings; USD in brackets for median payments)

\begin{tabular}{lllll}
\hline Insurance status & $\mathbf{N}^{\mathbf{a}}$ & $\mathbf{p 2 5}$ & $\begin{array}{l}\text { Median } \\
\text { (p50) (USD) }\end{array}$ & p75 \\
\hline None & 19 & 140,000 & $540,000(235)$ & $1,251,300$ \\
Weak & 4 & 117,000 & $281,500(122)$ & 516,500 \\
Strong & 14 & 0 & $0(0)$ & 35,000 \\
All respondents & ${ }^{3} 37$ & 2500 & $170,000(74)$ & 700,000 \\
\hline
\end{tabular}

${ }^{a} \mathrm{~N}$ : number of patients able to recall $70 \%$ or more of payments per recorded event

had cost TZS 410,000 and transport at least TZS 97,200: total TZS 812,200 (USD 353). This patient had declared monthly household income of just TZS 60,000 (USD 26). (Female patient, completed secondary, self-employed business).

There were many such examples of the pain and stress from biopsies delayed because patients could not pay to undergo them, nor to take them to a hospital with pathology services. These payments both delayed diagnosis and undermined patients' household finances - permanently if assets were sold.

\section{The private sector and insurance access: facilitation and inequality}

While expensive to access, the private sector had played a facilitating role in accelerating diagnosis for those able to pay or having access to insurance. Most (60\%) of all respondents held no insurance. The others held two different types: "strong" insurance, within which we include membership of the National Health Insurance Fund (NHIF) ${ }^{10}$ and/or private insurance funds such as AAR (31\%); or "weak" insurance such as membership of a Community Health Fund (CIF) with limited coverage or exemptions from certain facilities' payments $(10 \%){ }^{11}$ Strong insurance was held by $73 \%$ of professionals and $90 \%$ of those with higher education, but just $17 \%$ of interviewees with other occupations and 19\% with lower educational levels. Strong insurance very sharply reduced the level of OOP payments before diagnosis, reducing

\footnotetext{
${ }^{10}$ A social insurance fund for health care that has expanded from public employees to cover a wide range of groups and individuals; estimated population coverage $9 \%$ in 2019 (https://www.nhif.or.tz/pages/profile\#gsc.tab=0 consulted 22/07/21). NHIF offers various levels of cover for beneficiaries.

${ }^{11}$ Figures do not add to 100 because of rounding.
} 
Table 11 Impact of relative privilege

\begin{tabular}{llll}
\hline Item and measure & More privileged & More disadvantaged & Very low education \\
\hline Cumulative days to diagnosis (median) & 137 & 394 & 670 \\
Cumulative days from first health facility visit to diagnosis (median) & 134 & 200 & 599 \\
Number of moves between providers ${ }^{2}$ before diagnosis (median) & 1.5 & 3 & 3 \\
First facility visited was in private sector (\%) & $75 \%$ & $6 \%$ & 0 \\
Cumulative OOP payments up to diagnosis (TZS) (median) & 0 & 225,000 & 700,000
\end{tabular}

${ }^{a}$ All providers including health facilities, drug shops, pharmacies and traditional healers

the median payment to zero (Table 10). No-one without strong insurance escaped without any OOP payments.

Strong insurance also gave access to the private sector: $90 \%$ of those whose first visit was to a private health facility held strong insurance, and those respondents experienced much less churning and delay. The private sector had also facilitated cancer diagnosis for six patients who started their pathways in the public sector, but at a cost which could add to delay and financial burden.

Cases 6 and 7: strong insurance facilitating rapid private sector diagnosis A patient holding private insurance experienced severe breast pain. Despite reluctance, she was persuaded by work colleagues to go directly to the large private hospital, Aga Khan. There a mammogram and biopsy provided a diagnosis of breast cancer in 2 weeks. All charges were paid by insurance. (Female professional with higher education).

A second patient holding both NHIF and private insurance experienced severe stomach pain and vomiting and went to a private facility. There a CT scan identified a liver problem. She was advised to go to a second private hospital for an MRI and was then diagnosed with liver cancer in less than a month at Aga Khan hospital. Insurance paid all these costs. (Female professional with higher education).

Inequality-reinforcing factors in access to cancer diagnosis Several key socio-economic factors were thus mutually reinforcing in reducing delay before diagnosis: better education, professional occupation and strong insurance coverage. These characteristics of interviewees were associated with intermediate factors within the health system that reduced delays: private sector starts, fewer moves between providers in search of care, and a lower cost burden.

The combined regressive impact for our respondents of these cumulative influences is starkly demonstrated in Table 11. Respondents are divided into 12 "more privileged" individuals with at least two of the following characteristics: professional occupation, post-secondary education and strong insurance; 33 "more disadvantaged" people with primary or secondary education; and 17 individuals with below-primary or no formal education (Table 11).

The "more privileged" group experienced the shortest delays before diagnosis and the lowest levels of "churning". They had generally started their pathways in the private sector, and the median out-of-pocket spending of this group before diagnosis was zero. Conversely, those with very low education, though they had not started at lower level facilities than others starting in the public sector, had consistently the longest waits, and had paid the largest sums in OOP spending to reach a cancer diagnosis.

\section{Discussion}

Our core finding, summarised in Table 11, is the socially unjust patterning of these cancer patients' experiences by education, occupation and income. The greater the social and economic disadvantage, the longer the delay, the greater the stress of self-referral, and the higher the absolute financial burden. The findings also illustrate the mutually reinforcing effects of socio-economic disadvantage and public health system capability weaknesses. There are strong, inequality-reinforcing interlinkages between what are sometimes called [19] patient-mediated (e.g. socioeconomic status) versus health systemmediated (e.g. referral problems) delays to cancer care access.

The strength of these findings is their rootedness in patients' experience: there is a dearth of evidence in the literature on cancer patients' perspectives from lower income countries. In analysing patients' experiences up to diagnosis, this article extends the limited existing literature on the cost and barriers to accessing cancer care in Tanzania [14, 29-31]. While no statistical claim is made for generalisability to the Tanzanian population, the consistency of the findings within the data set, and their external consistency with other evidence including OOP payments as barriers to care and estimated drop-out 
from cancer care, support their relevance for policies aiming to move towards UHC including greater social justice in access to cancer care.

Key policy implications, largely consistent with existing literature, include the following. Diagnostic capacity in Tanzania is heavily concentrated in 7 zonal and national hospitals, located in 5 major cities in Tanzania. Only four consultant hospitals, in addition to some private and faith-based facilities, have a pathology laboratory ([12]: 8), meaning that regional hospitals frequently do not have the capacity to analyse biopsies. As some of our respondents experienced, such challenges potentially delay the diagnosis and referral of potential cancer patients [29, 32]. Furthermore, magnetic resonance imaging and computerized tomography scans are often not available at regional hospital level, meaning patients must travel to zonal or national facilities [33-35]. Strengthening the diagnostic skills and capabilities of the regional hospitals, including capability to undertake biopsies and laboratory pathology, implies substantial investment but would improve the referral role of facilities that are much more geographically accessible to patients: this could be a focus for external funding support.

Our findings on the high costs of reaching a diagnosis complement qualitative evidence from elsewhere in the region on OOP costs of accessing cancer care [36-39]. We add sharper evidence on the highly regressive impact of the OOP spending, including examples of impoverishment through sale of assets, and the impact of delays on costs, self-referral and travel in search of care. Our findings support the importance of policy towards diagnostics in UHC initiatives [40]. Policy changes that might reduce OOP cost and speed up diagnosis include subsidising diagnostic tests to reduce cost sharing and formalising public/private arrangements to enable greater access to testing infrastructure held in the private sector. Our findings confirm the benefits of insurance for speeding access to diagnosis through more rapid private sector response, and the impact of this on inequality of costs and speed of diagnosis. Financial reforms are required, consistent with the principles of UHC, that promote integration of financing schemes and improve financial support for the least well-off who lack insurance and struggle to meet OOP costs.

Cervical cancer screening is being extended systematically in Tanzania ([41]: 15); however, coverage remains limited and identified barriers to attendance include limited knowledge and local availability as well as anticipated cost of travel and the procedure itself $[8,42]$. This is consistent with our finding that just one patient interviewed had been diagnosed (after facility visits) through screening. Our evidence on delayed investigation of symptoms strongly suggests that more systematic screening has scope to reduce sharply diagnosis times for some cancers. However, realising potential requires initial diagnostic screening, such as visual inspection for cervical cancer, to be more rapidly confirmed by biopsies when required.

Our finding that those with lowest education faced the longest delays is consistent with existing literature on Tanzania and other African countries that suggests limited awareness among the wider population of symptoms of cancer, alongside stigmatisation and fear of screening and treatment, contribute towards late diagnosis of cancer, prompting calls for wider public information [6, 36, 43-48]. However, patients interviewed had showed no "lack of personal initiative" ([8]:1) in seeking care. Many had taken family, friends' and neighbours' advice, and were very active in selfreferral; use of traditional healers was often a response to health system delay.

Our evidence demonstrated however the limitations of formal referral as it is currently functioning for cancer patients, a weakness acknowledged within government policy ([49]: 10). While anthropological research has shown how oncologists and nurses may have to improvise' in the provision of cancer care in low income settings [50], this research illustrates the extent to which patients without strong insurance must also try to piece together care that is acceptable, affordable and available to them as they seek a diagnosis. This echoes a smaller qualitative study of cancer patients' experiences in Tanzania in suggesting the potential for misdiagnosis and provision of inappropriate, but often costly, initial treatment to contribute to late diagnosis [31].

In summary, this article demonstrates the extent to which health-seeking behaviour by our respondents was, as in other studies, shaped by economic hardship [21] and by perceived failings and limitations of the formal healthcare system $[48,51]$. However, just as aspects of disadvantage were shown to be mutually reinforcing, so partial solutions can potentially create a virtuous circle of interactions between better facility capabilities, lower charges, widening insurance, better information, strengthened referral pathways and less self-referred "churning". The central message is that policies directed at moving towards UHC need to focus particularly on alleviating the burden and barriers faced by the most disadvantaged.

An important limitation of this study is that respondents included only patients who had eventually received a diagnosis and were being treated in a hospital at the time the research was conducted. Many of those with cancer in Tanzania may not receive a diagnosis at all [12]. Our respondents' experience does however offer some implications for policy to speed up diagnosis, in order to 
identify cancers at earlier stages when treatment can be more effective.

\section{Conclusion}

Late diagnosis is a root cause, in Tanzania as in many low- and middle-income countries, of cancer treatment starting at advanced stages, undermining treatment efficacy and survival rates. While Tanzania's policy of free public sector cancer treatment has made treatment accessible to patients on low incomes and without insurance, reaching a diagnosis is shown, for a set of 62 cancer patients, to have been slower and more expensive the greater their socio-economic disadvantage.

These findings imply that moves towards UHC, responding to the rising need for cancer care, must focus particularly on reducing costs and other barriers faced by those with low education, low incomes and vulnerable employment status. Reducing these barriers to reaching a diagnosis can reduce delays, help to down-stage the moment at which cancers begin to be treated, and create movement towards greater social justice in the design of universal health coverage.

\author{
Abbreviations \\ CIF: Community Health Fund; LMICs: Low- and middle-income countries; \\ NHIF: National Health Insurance Fund; OOP: Out-of-pocket; ORCI: Ocean Road \\ Cancer Institute; TZS: Tanzanian Shillings; USD: United States dollars; UHC: \\ Universal Health Coverage.
}

\section{Supplementary Information}

The online version contains supplementary material available at https://doi. org/10.1186/s12913-021-07438-5.

\section{Additional file 1.}

\section{Acknowledgements}

This research forms part of a study entitled Innovation for Cancer Care in Africa (ICCA). Financial support is gratefully acknowledged from the Economic and Social Research Council (ESRC) UK, under the Global Challenges Research Fund, Inclusive Societies Initiative (reference ES/S000659/1). The content of this publication is the sole responsibility of the authors and does not necessarily reflect the views of the UK ESRC. The research team thank all the individuals and organizations who generously shared their time, experience, and materials for the purposes of this study including providers, patients, caregivers, and regulatory authorities. The research team is particularly grateful for the time and commitment of the cancer sufferers, many responding despite serious illness. The commitment and sensitivity of our interviewers Samwel Ebenezeri, Teddy Rucho, Nicholas Lusingu, Ikunda Njau, Rehema Paul, Wilfred Massau, Janeth Telekako, and Habambi Habambi is appreciated. Thanks also to participants in a workshop held in December 2019 in Dar es Salaam.

\section{Authors' contributions}

FSM led the research, including design and management of fieldwork, analysis of data, and design of paper structure and content. RN managed the fieldwork; shared the design and analysis of fieldwork data, and contributed to paper drafting. PGMM and TN contributed to the design of the fieldwork and analysis of data; both contributed to and reviewed content. MW led the quantitative analysis for the paper. CS designed the pathways data collection tool, and contributed to quantitative analysis and paper content. CC participated in design and undertaking of fieldwork and contributed to drafting. MM contributed to design of fieldwork, shared data analysis and led drafting. All authors contributed to the final version of the paper and read and approved the article for submission.

\section{Funding}

This research forms part of a study entitled Innovation for Cancer Care in Africa (ICCA). Financial support was provided by the Economic and Social Research Council (ESRC) UK, under the Global Challenges Research Fund, Inclusive Societies Initiative (reference ES/S000659/1). The funding body played no role in the design, data collection, analysis or interpretation of data, or in the writing of the manuscript.

\section{Availability of data and materials}

The project from which these data are drawn is ongoing. Data are not yet available in appropriate form for archiving. Consistent with ESRC, UK, requirements, data from the project will be archived for use by researchers at the end of the project. Information on the archiving schedule can be provided by authors on request.

\section{Declarations}

\section{Ethics approval and consent to participate}

Ethical review and research permits were provided in Tanzania by: the National Institute for Medical Research (NIMR); COSTECH; National Bureau of Statistics (NBS); PORALG; and Regional Offices in Dar Es Salaam, Pwani (Coast) and Tabora. Ethical review and permission for the project as a whole was provided by the Human Research Ethics Committee (HREC) of the Open University, UK. All participants signed consent forms specifying the objectives and content of the study, privacy and data security, voluntary participation, the right to refuse to answer any questions, and information on who to follow up regarding complaints or further information.

\section{Consent for publication}

All authors have approved the text for publication. All data from interviewees was fully anonymised before analysis, and there are no data from individuals.

\section{Competing interests}

The authors declare they have no competing interests.

\section{Author details}

${ }^{1}$ Economic and Social Research Foundation, 51 Uporoto Street, Ursino Estate, P.O Box 31226, Dar es Salaam, Tanzania. '2 Faculty of Arts and Social Sciences, The Open University, Walton Hall, Milton Keynes MK7 6AA, UK. ${ }^{3}$ Department of Behavioural Sciences, Muhimbili University of Heath and Allied Sciences, United Nations Rd, Dar es Salaam, Tanzania. ${ }^{4}$ International Institute of Social Studies, Erasmus University Rotterdam, Kortenaerkade 12, The Hague 2518 AX, The Netherlands.

Received: 29 August 2021 Accepted: 21 December 2021 Published online: 12 February 2022

\section{References}

1. World Bank. Country data:Tanzania. https://data.worldbank.org/country/ tanzania?view=chart last accessed 16 Nov 2021.

2. World Health Organization. Global Health Expenditure Data Base. https://apps. who.int/nha/database/NiewData/Indicators/en last accessed 16 Nov 2021.

3. United Republic of Tanzania. Statistical abstract 2019. Dar es Salaam: National Bureau of Statistics; 2020

4. Lyimo EP, Rumisha SF, Mremi IR, Mangu CD, Kishamawe C, Chiduo MG, et al. Cancer mortality patterns in Tanzania: A retrospective hospitalbased study, 2006-2015. JCO Global Oncol. 2020;6:224-32.

5. World Health Organization/International Agency for Research on Cancer (IARC). Globocan 2020. https://gco.iarc.fr/today/data/factsheets/popul ations/834-tanzania-united-republic-of-fact-sheets.pdf last accessed 29 Nov 2021. 
6. Henke A. Kluge U. Borde T. Mchome B. Serventi F. Henke O. Tanzanian women's knowledge about Cervical Cancer and HPV and their prevalence of positive VIA cervical screening results. Data from a Prevention and Awareness Campaign in Northern Tanzania, 2017-2019. Glob Health Action 2021; 14:1 DOI: https://doi.org/10.1080/16549716.2020. 1852780.

7. Shrime MG, Sekidde S, Linden A, Cohen JL, Weinstein MC. Salomon JA sustainable development in surgery: the health, poverty, and equity impacts of charitable surgery in Uganda. PLoS One. 2016;11(12):e0168867. https://doi.org/10.1371/journal.pone.0168867.

8. Mlange R, Matovelo D, Rambau P, Kidenya B. Patient and disease characteristics associated with late tumour stage at presentation of cervical cancer in northwestern Tanzania. BMC Womens Health. 2016;16:5. https:// doi.org/10.1186/s12905-016-0285-7.

9. United Republic of Tanzania [URT] Ministry of Health, Community Development, Gender, Elderly and Children (MHCDGEC). Tanzania Breast Health Care Assessment 2017. Dar es Salaam; 2017.

10. Ngoma T, Mandeli J, Holland JF. Downstaging cancer in rural Africa. Int J Cancer. 2014;136:2875-9.

11. United Republic of Tanzania. National Health Policy 2017. Non-Communicable Diseases. Dar es Salaam; 2017.

12. United Republic of Tanzania [URT] Ministry of Health and Social Welfare (MoHSW) National Cancer Control Strategy 2013-2022. Dar es Salaam 2012.

13. World Health Organization (WHO). WHO report on cancer: setting priorities, investing wisely and providing care for all. Geneva; $2020 \mathrm{https} / /$ www.who.int/publications/i/item/who-report-on-cancer-setting-prior ities-investing-wisely-and-providing-care-for-all downloaded 15 Dec 20.

14. Gesink MP, Chamberlain RM, Mwaiselage J, Kahesa C, Jackson K, Mueller W, et al. Quantifying the under-estimation of cervical cancer in remote regions of Tanzania. BMC Cancer. 2020;20:939. https://doi.org/10.1186/ s12885-020-07439-3.

15. Olson AC, Afyusisyec F, Eggerd J, Noyde D, Likondac B, Masaluc N, et al. Cancer incidence and treatment utilization patterns at a regional cancer center in Tanzania from 2008-2016: initial report of 2,772 cases. Cancer Epidemiol. 2020;67:101772.

16. Rotter T, Kugler J, Koch R, Gothe H, Twork S, van Oostrum JM, et al. The effects of clinical pathways on professional practice, patient outcomes, length of stay and hospital costs: Cochrane systematic review and metaanalysis. Eval Health Prof. 2012;35(1):3-27.

17. Dahlin S, Raharjo H. Relation between patient costs and patient pathways. Int J Health Care Qual Assess. 2019:32(1):246-59.

18. Martins T, Merrial SWD, Hamilton W. Routes to diagnosis of symptomatic cancer in sub-Saharan Africa: systematic review. BMJ Open. 2020;10:e038605. https://doi.org/10.1136/bmjopen-2020-038605.

19. Espina C, McKenzie F, dos-Santos-Silva I. Delayed presentation and diagnosis of breast cancer in African women: a systematic review. Ann Epidemiol. 2017;27:659e671.

20. Moodley J, Cairncross L, Naiker T, Constant D. From symptom discovery to treatment - women's pathways to breast cancer care: a cross-sectional study. BMC Cancer. 2018;18:312.

21. Grosse Frie K, Kamaté B, Traoré CB, Coulibaly B, Mallé B, Kantelhardt EJ. Health system organisation and patient pathways: breast care patients' trajectories and medical doctors' practice in Mali. BMC Public Health. 2019;19:204.

22. Mhalu G, Hella J, Mhimbira F, Said K, Mosabi T, Mlacha YP, et al. Pathways and associated costs of care in patients with confirmed and presumptive tuberculosis in Tanzania: A cross-sectional study. BMJ Open. 2019;9:e025079. https://doi.org/10.1136/bmjopen-2018-025079.

23. Muraya K, Ogutu M, Mwadhi M, Mikusa J, Okinyi M, Magawi C, et al. Applying a gender lens to understand pathways through care for acutely ill young children in Kenyan urban informal settlements. Int J Equity Health. 2021;20:17.

24. Maxwell JA. Using numbers in qualitative research. Qual Inq. 2010;16(6):475-82.

25. United Republic of Tanzania. 2017-18 Household Budget Survey: Key Indicators Report. Dodoma: National Bureau of Statistics; 2019. https:// www.nbs.go.tz/nbs/takwimu/hbs/2017_18_HBS_Key_Indicators_ Report_Engl.pdf. Accessed 3 Jan 2022.

26. United Republic of Tanzania. Labour Market Information in Tanzania, 2018. Dodoma: National Bureau of Statistics; 2018 https://www.nbs.go.tz/
nbs/takwimu/labour/Employment_Estimates_for_Tanzania_Mainland20 18.pdf. Accessed 29 Nov 2021.

27. United Republic of Tanzania. Integrated labour force survey, analytical report, Tanzania mainland 2014. Dar es Salaam: National Bureau of Statistics; 2015.

28. Kanté AM, Exavery A, Phillips JF, Jackson EF. Why women bypass front-line health facility services in pursuit of obstetric care provided elsewhere: a case study in three rural districts of Tanzania. Trop Med Int Health. 2021:4:504-14.

29. Shroeder K, Saxton A, Chao C, Wechsler DS, Chao N, McDade J, et al. Pediatric cancer in northern Tanzania: evaluation of diagnosis, treatment and outcomes. Glob Oncol. 2017. https://doi.org/10.1200/JGO.2016.009027.

30. Esmaili EB, Steward KA, Masalu NA, Schroeder KM. Qualitative analysis of palliative care for pediatric patients with cancer at Bugando medical Centre: an evaluation of barriers to providing end-of-life care in a resourcelimited setting. J Glob Oncol. 2018. https://doi.org/10.1200/JGO.17.00047.

31. Kohi TW, von Essen L, Masika GM, Gottvall M, Dol J. Cancer-related concerns and needs among young adults and children on cancer treatment in Tanzania: a qualitative study. BMC Cancer. 2019;19:82.

32. Stefan DC, Masalu N, Ngendahayo L, Amador D, Botteghi M, Mendy M, et al. Pathology and oncology in Africa: education and training for the future in cancer research - east African regional meeting. Infect Agents Cancer. 2015;10:48.

33. The Citizen. Villagers'long trek for scans. 9 December 2015; https://www. thecitizen.co.tz/tanzania/news/feature-villagers-long-trek-for-scans2540796 Accessed 8 Dec 2021.

34. Goldberg J. Tanzania country profile. Rad-Aid.org. 2017; https://rad-aid. org/wp-content/uploads/Country-Report-Tanzania_Goldberg.pdf Accessed 8 Dec 2021.

35. Daily News. Bugando to install MRI machine next month. 31 January 2020; https://www.habarileo.co.tz/habari/2020-01-315e341bb7a46da. aspx Accessed 8 Dec 2021.

36. Makau-Barasa LK, Greene SB, Othieno-Abinya NA, Wheeler S, Skinner A, Bennett AV. Improving access to cancer testing and treatment in Kenya. J Glob Oncol. 2017. https://doi.org/10.1200/JGO.2017.010124.

37. Atieno MO, Opanga S, Martin A, Kurdi A, Godman B. Pilot study assessing the direct medical cost of treating patients with cancer in Kenya; findings and implications for the future. J Med Econ. 2018;21(9):878-87.

38. Guzha NT, Thebe T, Butler N, Valodia PN. Development of a method to determine the cost of breast cancer treatment with chemotherapy at Groote Schuur hospital, Cape Town, South Africa. South Afr Med J. 2020;110(4):296-301.

39. Mattila PO, Babarr Z-U-D, Suleman F. Assessing the prices and affordability of oncology medicines for three common cancers within the private sector of South Africa. BMC Health Serv Res. 2021;21:661.

40. Boehme C, Hannay E, Pai M. Promoting diagnostics as a global good. Nat Med. 2021:27:367-8.

41. United Republic of Tanzania. National Cancer Treatment Guidelines. 1st edition. Ministry of Health, Community Development, Gender, Elderly and Children, Tanzania: 2020. https://www.orci.or.tz/5781-2/ Accessed 29 Nov 2021.

42. Cunningham MS, Skrastins E, Fitzpatrick R, Jindal P, Oneko O, Yeates K, et al. Cervical cancer screening and HPV vaccine acceptability among rural and urban women in Kilimanjaro region Tanzania. BMJ Open. 2015. https://doi.org/10.1136/bmjopen-2014-005828.

43. Mulemi B. Coping with cancer and adversity: hospital ethnography in Kenya. Leiden: African Studies Centre; 2010.

44. Morse EP, Maegga B, Joseph G, Miesfeldt S. Breast cancer knowledge, beliefs and screening practices among women seeking care at district hospitals in Dar Es Salaam Tanzania. Breast Cancer Basic Clin Res. 2014;8:73-9.

45. Ngutu M, Nyamongo IK. Exploring the barriers to health care and psychosocial challenges in cervical cancer management in Kenya. Int J Women's Health. 2015;7:791-8.

46. Alwash Z, Henke O, Serventi F, Kantelhardt EJ. Staff perspectives toward challenges in a newly established cancer center in Tanzania: a qualitative study. J Glob Oncol. 2019;5:1-8

47. Pierz AJ, Randall TC, Castle PE, Adedimeji A, Ingabire C, Kubwimana G, et al. A scoping review: facilitators and barriers of cervical cancer screening and early diagnosis of breast cancer in sub-Saharan African health settings. Gynecologic. Oncol Rep. 2020;33:100605. 
48. Mwaka AD, Walter FM, Scott S, Harries J, Wabinga H, Moodley J. Symptom appraisal, help-seeking and perceived barriers to healthcare seeking in Uganda: an exploratory study among women with potential symptoms of breast and cervical cancer. BMJ Open. 2021. https://doi.org/10.1136/ bmjopen-2020-041365.

49. United Republic of Tanzania. Strategic plan and action plan for the prevention and control of non communicable diseases in Tanzania 2016-2020. 2016. https://extranet.who.int/nutrition/gina/sites/default/ files/TZA-2016-2020 NCD\%20Strategic\%20Plan.pdf Accessed 8 Dec 2021.

50. Livingstone J. Improvising medicine: an African oncology ward in an emerging cancer epidemic. Durham: Duke University Press; 2012

51. Githaiga JN. When 'chemo is failing'...'the illness is indigenous'. Therapeutic pluralism and reclaiming agency: family cancer caregivers' experiences in Nairobi. J East Afr Stud. 2017;11(2):310-28.

\section{Publisher's Note}

Springer Nature remains neutral with regard to jurisdictional claims in published maps and institutional affiliations.

- fast, convenient online submission

- thorough peer review by experienced researchers in your field

- rapid publication on acceptance

- support for research data, including large and complex data types

- gold Open Access which fosters wider collaboration and increased citations

- maximum visibility for your research: over $100 \mathrm{M}$ website views per year

At BMC, research is always in progress.

Learn more biomedcentral.com/submissions 